\title{
Electronic Effects in Horse Liver Alcohol Dehydrogenase Catalysis
}

\author{
CHARLES H. BLOMQUIS T*
}

Medicinska Nobelinstitutet, Biokemiska avdelningen, Stockholm, Sweden

Kinetic studies of the horse liver alcohol dehydrogenase-catalyzed reduction of benzaldehyde and a series of para-substituted benzaldehyde compounds have been made.** There was no apparent deviation from the ordered mechanism postulated for the reaction with any of the substrates examined. The values of the kinetic constants ${ }^{14}$ $\Phi_{0}$ and $\Phi_{1}$ were independent of the nature of the aldehyde substrate. The values of $1 / \Phi_{2}$ increased with the increasing electron-withdrawing power ( $\sigma$ value) of the para-substituent. The results are consistent with the postulated reaction mechanism involving the transfer of a hydride ion to or from an alcoholate ion intermediate. ${ }^{6,8,9}$

$\mathrm{n}$ the basis of extensive kinetic studies, ${ }^{1-4}$ the reaction catalyzed by horse liver alcohol dehydrogenase can be characterized by the following sequence of reactions:

$$
\begin{gathered}
\mathrm{E}+\mathrm{S}_{1} \underset{k_{-1}}{\stackrel{k_{1}}{\rightleftharpoons}} \mathrm{ES}_{1} \\
\mathrm{ES}_{1}+\mathrm{S}_{2} \stackrel{k_{2}}{\rightleftharpoons} \mathrm{ES}_{1} \mathrm{~S}_{2} \stackrel{k}{\rightleftharpoons} \mathrm{ES}_{1}{ }^{\prime} \mathrm{S}_{2}{ }^{\prime} \stackrel{k_{-2}{ }^{\prime}}{\rightleftharpoons} \mathrm{ES}_{1}{ }^{\prime}+\mathrm{S}_{2}{ }^{\prime} \\
\mathrm{ES}_{1}{ }^{\prime} \underset{k_{1}^{\prime}}{\rightleftharpoons} \mathrm{E}+\mathrm{S}_{1}{ }^{\prime}
\end{gathered}
$$

* Present address: Biomedical Research Group, Los Alamos Scientific Laboratory, University of California, Los Alamos, New Mexico, U.S.A.

** The following abbreviations are used: NAD, nicotinamide adenine dinucleotide; NADH, reduced nicotinamide adenine dinucleotide; $\mathrm{E}$, alcohol dehydrogenase; $\mathrm{S}_{1}, \mathrm{NADH} ; \mathrm{S}_{2}$, aldehyde; $\mathrm{S}_{1}{ }^{\prime}, \mathrm{NAD}$; and $\mathrm{S}_{2}{ }^{\prime}$, alcohol. 
The sequence is an ordered one; the coenzyme adds first, followed by the alcohol or aldehyde substrate, and the rate-limiting step in either direction (alcohol oxidation or aldehyde reduction) at saturating substrate concentrations for the liver enzyme is the dissociation of the enzyme-coenzyme product complex $\left(\mathrm{ES}_{1}{ }^{\prime} \rightleftharpoons \mathrm{E}+\mathrm{S}_{1}{ }^{\prime}\right.$ or $\left.\mathrm{ES}_{1} \rightleftharpoons \mathrm{E}+\mathrm{S}_{1}\right)$.

From the observations of a direct hydrogen transfer, ${ }^{5}$ of deuterium isotope effects, ${ }^{6}$ and from studies of model compounds, ${ }^{7}$ it has been postulated ${ }^{6,8,9}$ that the reaction catalyzed by liver alcohol dehydrogenase involves the direct transfer of a hydride ion via a mechanism analogous to that put forward for the Meerwein-Ponndorf-Verley-Oppenauer reaction. ${ }^{10,11}$ It has been proposed that in the enzyme reaction the zinc atom at the "active center" induces the necessary polarization of the carbon-oxygen bond of the substrate (giving rise to an alcoholate ion) to allow for the hydride ion transfer.

In an attempt to clarify further the nature of the mechanism of alcohol dehydrogenase catalysis, kinetic studies have been conducted of the reduction of benzaldehyde and some para-substituted benzaldehyde derivatives. The results of these studies and the conclusions with respect to possible electronic effects on the reaction mechanism form the body of this report.

\section{EXPERIMENTAL}

Materials. Aldehyde substrates were obtained from commercial sources. Benzaldehyde, $p$-methyl-, and $p$-methoxybenzaldehyde were distilled immediately before use. A middle fraction was collected, and stock solutions in $0.1 \mu$ phosphate buffer, $\mathrm{pH} 7.0$, were stored in tightly stoppered tubes in the dark until used. During the kinetic experiments the reaction mixtures in the fluorometer cuvettes were also stored in the dark. $p$-Chloroand $p$-nitrobenzaldehyde were recrystallized from water and dried in vacuo. Melting points agreed to within $1^{\circ} \mathrm{C}$ with published values. Stock solutions were prepared in $0.1 \mu$ phosphate-0.05 M glycerol, $\mathrm{pH}$ 7.0.

NADH was obtained from Sigma Chemical Corporation and used without further purification. The manufacturer's assay indicated 97-98 \% purity. The 260/340 $\mathrm{m} \mu$ optical density ratio $\left(0.2 \mathrm{M} \mathrm{Na}_{2} \mathrm{HPO}_{4}, \mathrm{pH} \mathrm{9.9)}\right.$ varied from 3.6 to 3.8 with various preparations used throughout the series of experiments. Stock solutions $(100-400 \mu \mathrm{M})$

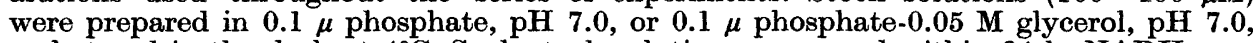
and stored in the dark at $4^{\circ} \mathrm{C}$. Such stock solutions were used within $24 \mathrm{~h}$. NADH concentration was estimated using an extinction coefficient at $340 \mathrm{~m} \mu$ of $6.22 \mathrm{mM}^{-1} \mathrm{~cm}^{-1}$.

Alcohol dehydrogenase was prepared from horse liver by the procedure of Yonetani. ${ }^{15}$ This procedure is a modification of Dalziel's method ${ }^{16}$ with the column chromatography steps being eliminated. The enzyme was recrystallized from $10 \%$ ethanol and then two or three times from $6 \%$ ethanol. Recrystallized enzyme was stored at $-15^{\circ} \mathrm{C}$ in $33 \%$ ethanol. For kinetic studies samples of enzyme were dissolved in $0.05 \mathrm{M}$ phosphate$\mathrm{NH}_{3}, \mathrm{pH} 9.5$, and dialyzed against $3-4$ changes of $0.1 \mu$ phosphate, $\mathrm{pH} 7.0$, at $4^{\circ} \mathrm{C}$. Activity was estimated according to the method of Dalziel, ${ }^{17}$ as modified by Theorell and McKinley-McKee. ${ }^{29}$ The extinction coefficient at $280 \mathrm{~m} \mu$ for alcohol dehydrogenase was taken as $0.455 \mathrm{mg}^{-1} \mathrm{~cm}^{2}$. With three enzyme preparations used throughout the series of experiments the enzyme purity was $92-98 \%$.

Methods. Initial reaction velocities were determined fluorometrically. The technique and apparatus have been described previously. ${ }^{18} \mathrm{~A}$ small volume of enzyme solution was added to a reaction cuvette containing aldehyde and NADH in $0.1 \mu$ phosphate or $0.1 \mu$ phosphate- $0.05 \mathrm{M}$ glycerol at $23.5^{\circ} \mathrm{C}$. The decrease in intensity of NADH fluorescence was recorded for 2-3 min. Initial velocities were estimated by extrapolation of the curve to zero time and constructing the tangent to the curve at this point. In the experiments with $p$-chloro- and $p$-nitrobenzaldehyde a French curve was used to construct the tangent to the recorded curve for the estimation of initial velocity. The alcohol 
dehydrogenase concentration in these experiments was $3-8 \mathrm{~m} \mu \mathrm{N}$, and the highest possible sensitivity settings on the fluorometer were used. Corrections were made for the self-quenching of NADH fluorescence. Initial velocity as a function of aldehyde concentration was determined at a series of NADH concentrations. Triplicate or duplicate determinations were made for each aldehyde concentration at 3 or 4 different coenzyme concentrations. Lineweaver-Burk plots (1/velocity vs. $1 /$ [substrate]) of the initial rate data were constructed visually or by using a least-squares method with equal weighting given to each point. Secondary plots of intercepts and slopes as functions of reciprocal NADH concentration, used to evaluate the coefficients in the rate equation $e / v_{0}=$ $\Phi_{0}+\Phi_{1} / S_{1}+\Phi_{2} / S_{2}+\Phi_{12} / S_{1} S_{2}$, as given by Dalziel ${ }^{14}$, were constructed in a similar manner. In the above expression the symbols are $e$, enzyme concentration; $v_{0}$, reaction velocity; $S_{1}, \mathrm{NADH}$ concentration; $S_{2}$, aldehyde concentration; and $\Phi_{0}, \Phi_{1}, \Phi_{2}$, and $\Phi_{12}$, kinetic coefficients related to the rate constants for the reaction sequence given in the introductory section by the expressions: ${ }^{2}$

$$
\Phi_{0}=1 / k_{-1}^{\prime} ; \Phi_{1}=1 / k_{1} ; \text { and } \Phi_{2}=\frac{1+\left(k_{-2} / k\right)+\left(k_{-2} k^{\prime} / k_{2}{ }^{\prime} k\right)}{k_{2}}
$$

\section{RESULTS}

Because the kinetic coefficient of particular interest for this study was $\Phi_{2}$ (see Discussion), initial studies were made of the reduction of benzaldehyde and the $p-\mathrm{CH}_{3}$ - and $p$ - $\mathrm{CH}_{3} \mathrm{O}$-derivatives at high $\mathrm{NADH}$ concentrations $(\sim 140$ $\mu \mathrm{M})$, the rationale for this approach being that the slope and intercepts of a Lineweaver-Burk plot of such data would approximate the values of $\Phi_{0}$ and $\Phi_{2}$ at infinite NADH concentration. The terms $\Phi_{1} / \mathrm{S}_{1}$ and $\Phi_{12} / \mathrm{S}_{1} \mathrm{~S}_{2}$ approach zero under these conditions. However, two principal difficulties were encountered. At such high concentrations of NADH the quenching factor necessary

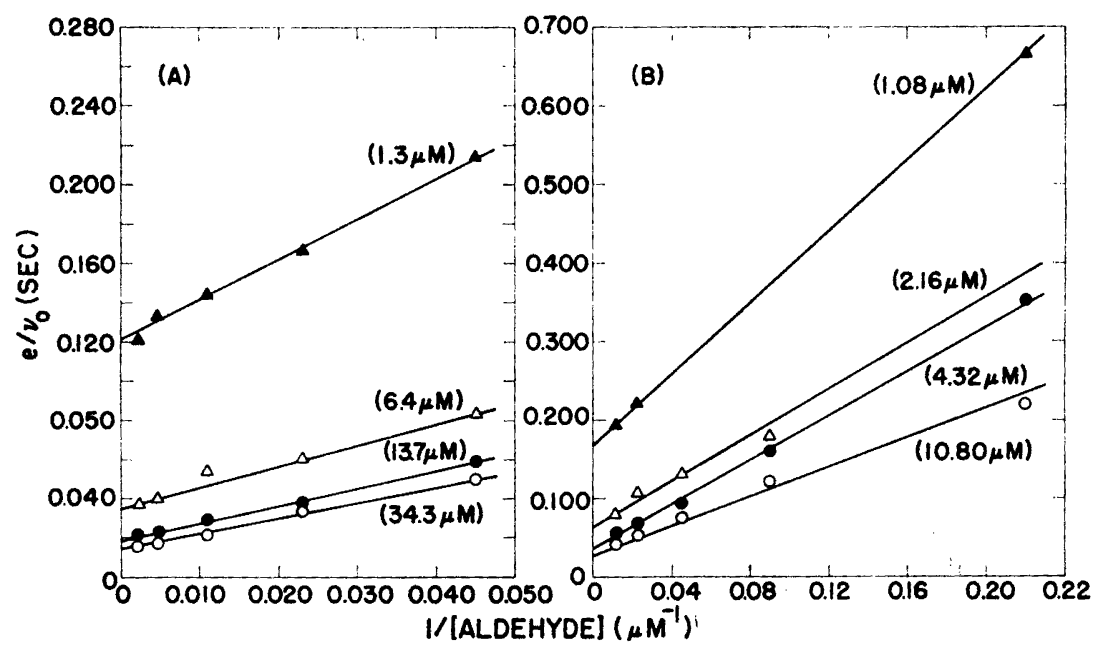

Fig. 1. (A) Benzaldehyde primary plot: variation of initial rate, $e / v_{0}$, at $\mathrm{pH} 7.0,23.5^{\circ} \mathrm{C}$, in $0.1 \mu$ phosphate, with the reciprocal of the benzaldehyde concentration for several constant NADH concentrations indicated in parentheses. (B) Benzaldehyde primary plot: variation of initial rate, $e / v_{0}$, at $\mathrm{pH} 7.0,23.5^{\circ} \mathrm{C}$, in $0.1 \mu$ phosphate- $0.05 \mathrm{M}$ glycerol, with the reciprocal of the benzaldehyde concentration for several constant NADH concentrations indicated in parentheses.

Acta Chem. Scand. 20 (1966) No. 7 


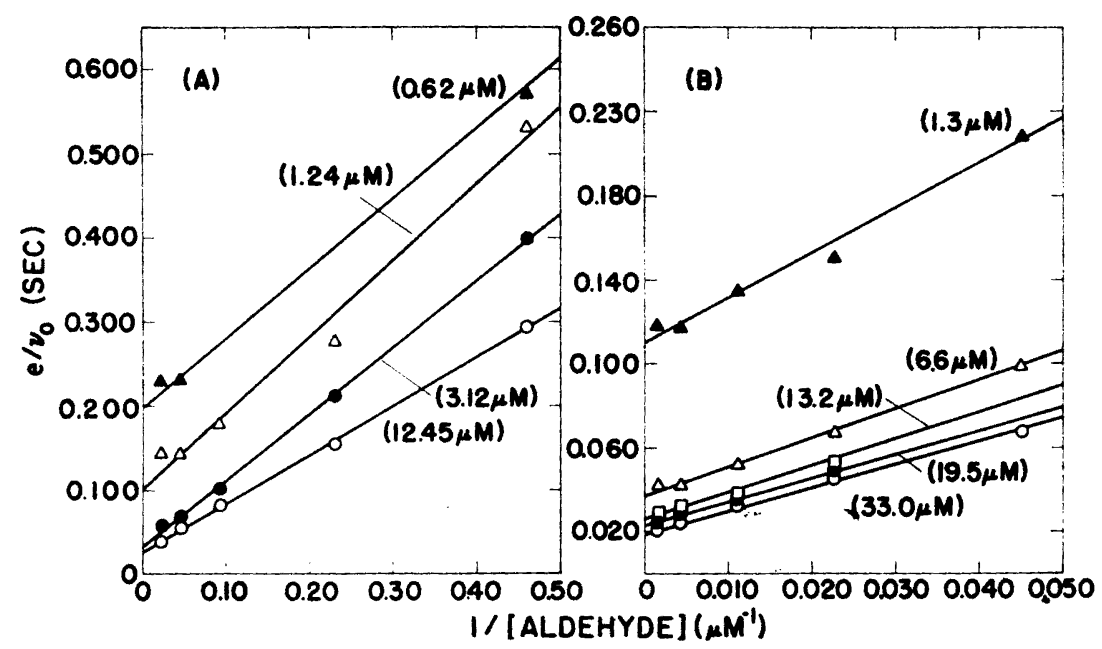

Fig. 2. (A) $p$-Methylbenzaldehyde primary plot: variation of initial rate, $e / v_{0}$, at $\mathrm{pH} 7.0$, $23.5^{\circ} \mathrm{C}$, in $0.1 \mu$ phosphate, with the reciprocal of the $p$-methylbenzaldehyde concentration for several constant NADH concentrations indicated in parentheses. (B) $p$-Methoxybenzaldehyde primary plot: variation of initial rate, $e / v_{0}$, at $\mathrm{pH} 7.0,23.5^{\circ} \mathrm{C}$, in $0.1 \mu$ phosphate, with the reciprocal of the $p$-methoxybenzaldehyde concentration for several constant NADH concentrations indicated in parentheses.

to quantitate the coenzyme concentration was high and unreliable. A second problem was the instability of the aldehyde substrates. For these reasons, initial velocity as a function of aldehyde concentration was measured at a

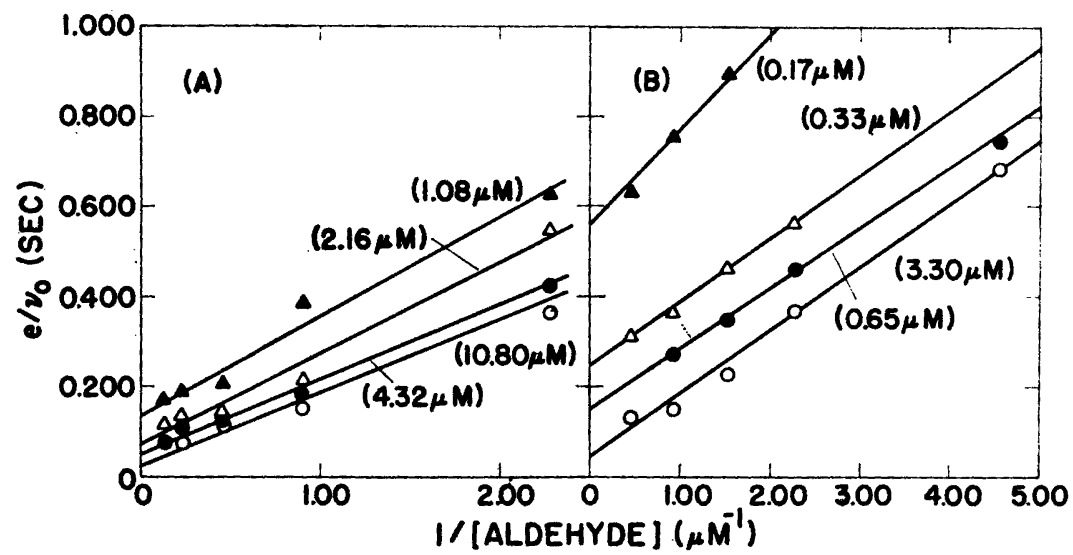

Fig. 3. (A) $p$-Chlorobenzaldehyde primary plot: variation of initial rate, $e / v_{0}$, at $\mathrm{pH} 7.0$, $23.5^{\circ} \mathrm{C}$, in $0.1 \mu$ phosphate-0.05 $\mathrm{M}$ glycerol, with the reciprocal of the $p$-chlorobenzaldehyde concentration for several constant NADH concentrations indicated in parentheses. (B) $p$-Nitrobenzaldehyde primary plot: variation of initial rate, $e / v_{0}$, at $\mathrm{pH} 7.0,23.5^{\circ} \mathrm{C}$, in $0.1 \mu$ phosphate-0.05 $\mathrm{M}$ glycerol, with the reciprocal of the $p$-nitrobenzaldehyde concentration for several constant NADH concentrations indicated in parentheses. 

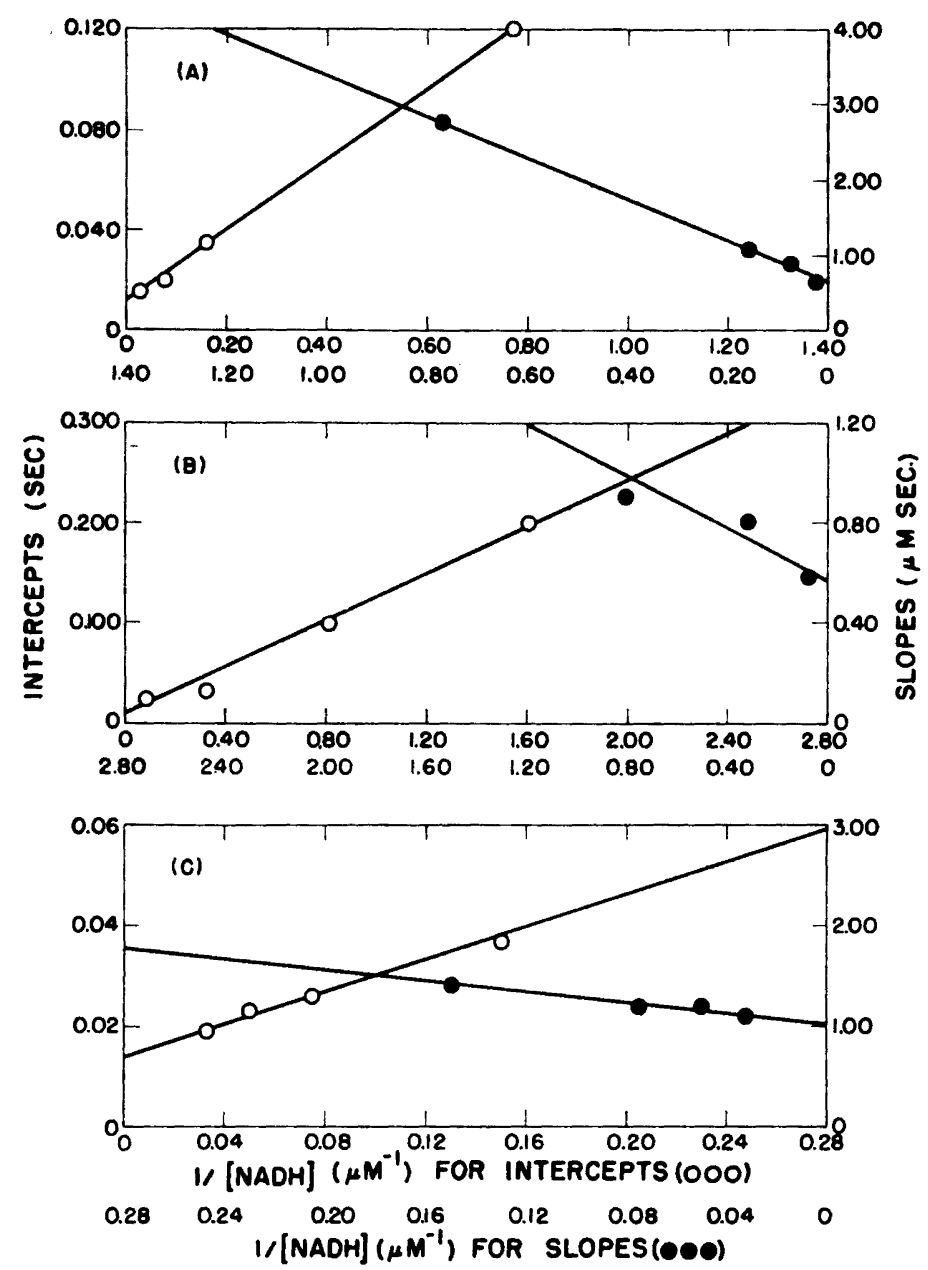

Fig. 4. (A) Benzaldehyde secondary plots: variation of intercepts and slopes with the reciprocal of the NADH concentration. Primary data are given in Fig. 1 (A). $\Phi$ Values from slopes and intercepts are given in Table 1. (B) $p$-Methylbenzaldehyde secondary plots: variation of intercepts and slopes with the reciprocal of the NADH concentration. Primary data are given in Fig. 2 (A). $\Phi$ Values from slopes and intercepts are given in Table 1. (C) $p$-Methoxybenzaldehyde secondary plots: variation of intercepts and slopes with the reciprocal of the NADH concentration. Primary data are given in Fig. 2 (B). $\Phi$ Values from slopes and intercepts are given in Table 1.

series of initial NADH concentrations. Also, precautions were taken to minimize the exposure of the labile substrates to light. Such instability has been previously reported in studies of aldehyde dehydrogenase. ${ }^{19}$

Plots of the initial rate data for the reduction of the series of aldehydes at $\mathrm{pH} 7.0$ and secondary plots of slopes and intercepts are shown in Figs.

Acta Chem. Scand. 20 (1966) No. 7 

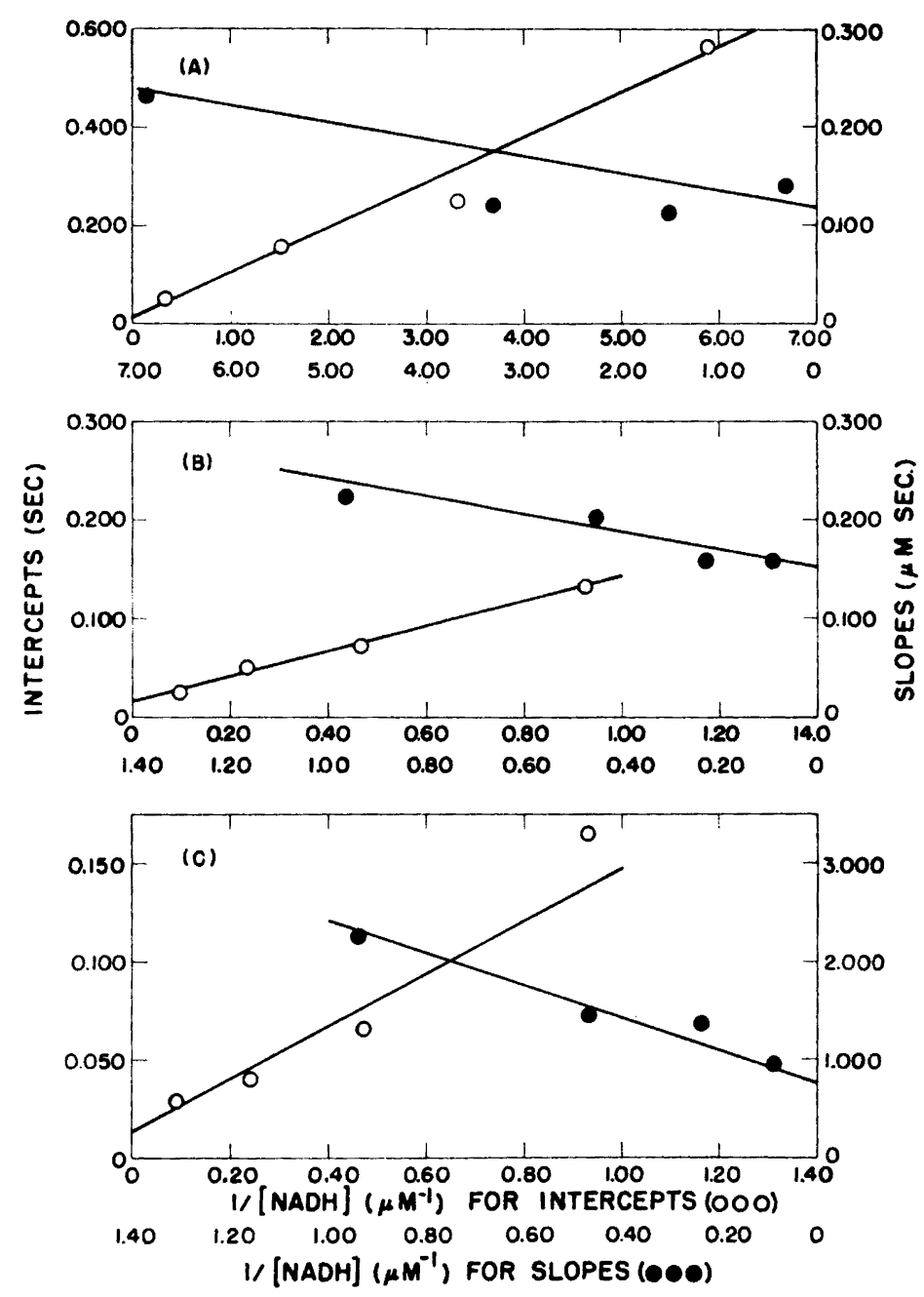

Fig. 5. (A) $p$-Nitrobenzaldehyde secondary plots: variation of intercepts and slopes with the reciprocal of the NADH concentration. Primary data are given in Fig. 3 (B). $\Phi$ Values from slopes and intercepts are given in Table 1. (B) $p$-Chlorobenzaldehyde secondary plots: variation of intercepts and slopes with the reciprocal of the NADH concentration. Primary data are given in Fig. 3 (A). $\Phi$ Values from slopes and intercepts are given in Table 1. (C) Benzaldehyde secondary plots: variation of intercepts and slopes with the reciprocal of the NADH concentration. Primary data are given in Fig. 1 (B). $\Phi$ Values from slopes and intercepts are given in Table 1 .

1-5. The slopes and intercepts of these secondary plots were used to evaluate the kinetic coefficients given in Table 1. The points shown in the graphs of the primary data are the average values of two or three determinations. The agreement between values was 3-12\%, with the larger deviations being 
Table 1. Kinetic coefficients for aromatic aldehydes. Details of the evaluation of the coefficients are given in the text.

\begin{tabular}{|c|c|c|c|c|c|c|}
\hline Compound & $\begin{array}{c}\Phi_{0} \\
\text { sec }\end{array}$ & $\begin{array}{c}\Phi_{1} \\
\mu \mathrm{M} \\
\text { sec }\end{array}$ & $\begin{array}{c}\Phi_{2} \\
\mu \mathrm{M} \\
\text { sec }\end{array}$ & $\begin{array}{c}\Phi_{12} \\
\mu \mathbf{M}^{2} \\
\text { sec }\end{array}$ & $\begin{array}{l}1 / \Phi_{2} \\
\mu \mathrm{M}^{-1} \\
\sec ^{-1}\end{array}$ & Medium* \\
\hline$p$-Methoxybenzaldehyde & 0.014 & 0.170 & 1.04 & 2.60 & 0.96 & \multirow{6}{*}{$\begin{array}{l}0.1 \mu \text { phosphate } \\
0.1 \mu \text { phosphate } \\
0.1 \mu \text { phosphate } \\
0.1 \mu \text { phosphate } \\
0.05 \mathrm{M} \text { glycerol } \\
0.1 \mu \text { phosphate } \\
0.05 \mathrm{M} \text { glycerol } \\
0.1 \mu \text { phosphate } \\
0.05 \mathrm{M} \text { glycerol }\end{array}$} \\
\hline$p$-Methylbenzaldehyde & 0.011 & 0.116 & 0.57 & 0.5 & 1.75 & \\
\hline Benzaldehyde & 0.012 & 0.142 & 0.60 & 3.26 & 1.67 & \\
\hline & 0.015 & 0.130 & 0.75 & 1.68 & 1.33 & \\
\hline$p$-Chlorobenzaldehyde & 0.014 & 0.131 & 0.16 & 0.08 & 6.25 & \\
\hline$p$-Nitrobenzaldehyde & 0.015 & 0.095 & 0.12 & 0.02 & 8.33 & \\
\hline
\end{tabular}

${ }^{*}$ At pH 7.0.

observed at lower substrate concentrations. Because of the low solubility of the $p$-chloro- and $p$-nitrobenzaldehyde compounds in water, it was necessary to use $0.05 \mathrm{M}$ glycerol to bring them into solution. As estimated from a comparison of the kinetic data for benzaldehyde in $0.1 \mu$ phosphate and $0.1 \mu$ phosphate-0.05 M glycerol, the glycerol at this concentration had no obvious effect on the reaction. A second problem with regard to the $p$-chloro- and $p$-nitrobenzaldehyde compounds was the observation of a marked substrate inhibition. For this reason, initial velocities were estimated with aldehyde concentrations of $8.8 \mu \mathrm{M}$ or less for $p$-chlorobenzaldehyde and $2.2 \mu \mathrm{M}$ or less for $p$-nitrobenzaldehyde. At the concentrations of aldehyde and nucleotide used, no such inhibition was observed with $p$-methoxy-, $p$-methyl-, or benzaldehyde. Such substrate inhibition has also been observed with these aldehydes in the liver aldehyde dehydrogenase reaction, ${ }^{19}$ and fluoro- and chloroethanol have been observed to inhibit the alcohol dehydrogenase reaction..$^{20,21}$

To evaluate possible electronic effects due to the para-substituent of the aldehyde substrate, a Hammett plot $^{13}$ of

$$
\log \left(\frac{\left[1 / \Phi_{2} \text {-substituted aldehyde }\right]}{\left[1 / \Phi_{2} \text {-benzaldehyde }\right]} \times 100\right) \text { vs. } \sigma
$$

was constructed and is shown in Fig. 6 .

\section{DISCUSSION}

From the data presented in Table 1 it can be seen that there is excellent agreement among the $\Phi_{0}$ values observed for the various substrates, although in all cases they are somewhat higher than the values obtained for acetaldehyde using highly purified coenzyme preparations. ${ }^{2}$ Reasonable agreement is observed also among the $\Phi_{1}$ values given in Table 1 . The possible errors in

Acta Chem. Scand. 20 (1966) No. 7 


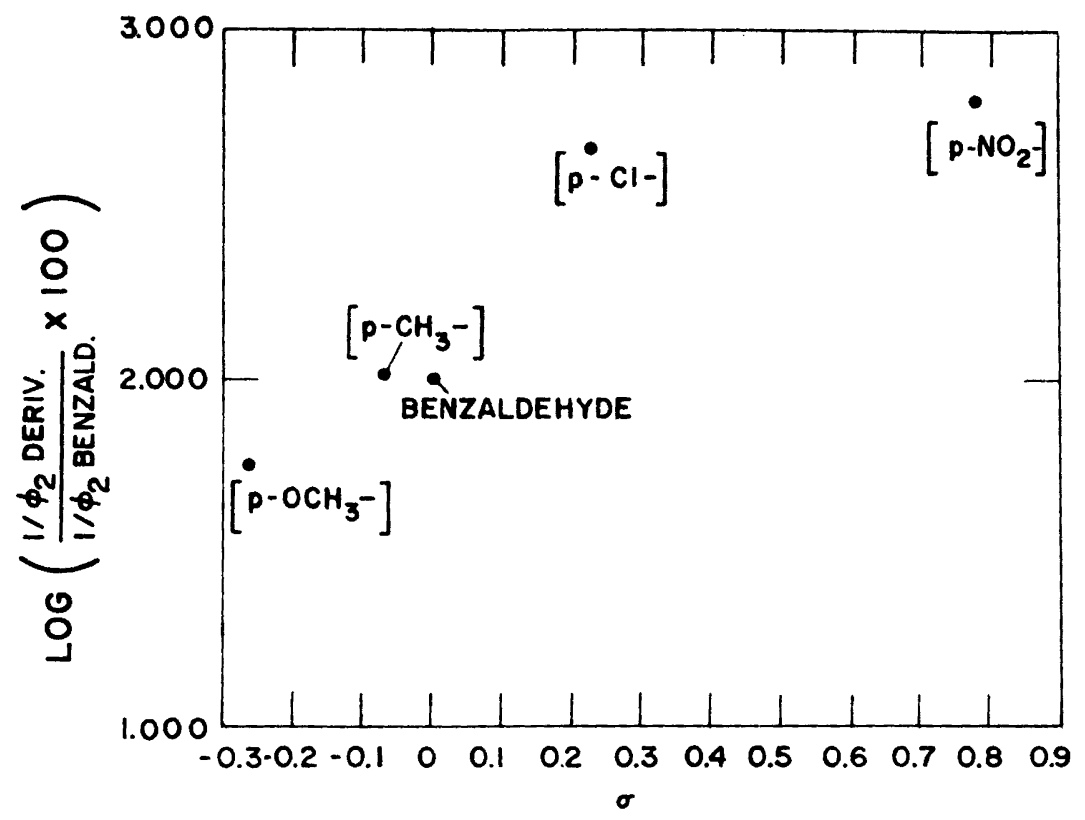

Fig. 6. Hammett plot:

$$
\log \left(\frac{\left[1 / \Phi_{2} \text { derivative }\right]}{\left[1 / \Phi_{2} \text { benzaldehyde }\right]} \times 100\right) v s .
$$

Hammett substituent constant. $\sigma$ Values taken from Ref. 13. $1 / \Phi_{2}$ ratios based on data obtained in $0.1 \mu$ phosphate, $\mathrm{pH} 7.0\left(p-\mathrm{CH}_{3} \mathrm{O}, p-\mathrm{CH}_{3}\right)$, or in $0.1 \mu$ phosphate-0.05 $\mathrm{M}$ glycerol, $\mathrm{pH} 7.0\left(p-\mathrm{Cl}, p-\mathrm{NO}_{2}\right)$.

the estimation of $\Phi_{1}$ values are greater and in the experiments reported here are further increased by the instability of aldehydes (benzaldehyde, $p$-methyl-, and $p$-methoxybenzaldehyde), by the short range of concentrations studied with the $p$-chloro- and $p$-nitro-derivatives and by the fact that velocity estimates for the $p$-nitro- and $p$-chloro-derivatives were made using extremely low concentrations of aldehyde and coenzyme. A complete evaluation of the reaction kinetics using the Dalziel criteria is not possible from a study of only the aldehyde side of the reaction. ${ }^{14}$ However, two criteria are satisfied. The $\Phi_{0}$ and $\Phi_{1}$ values appear to be independent of the nature of the aldehyde substrate, and the values are in good agreement with those previously observed with commercial coenzyme preparations in the acetaldehyde-ethanol and butyraldehyde-butanol reactions. ${ }^{22}$ On the basis of these data, the most reasonable conclusion is that the ordered mechanism indicated in the introductory section is applicable to these substrates.

The values of $\Phi_{2}$ are of particular importance in this study as they would be expected to reflect alterations in substrate reactivity due to substitution and thus yield more information as to the mechanism of the reaction. For purposes of discussion, $1 / \Phi_{2}$ has been used even though the interpretation of 
this kinetic coefficient in terms of rate constants is unclear. For the formulation given in the introductory section,

$$
\Phi_{2}=\frac{1+\left(k_{-2} / k\right)+\left(k_{-2} k^{\prime} / k_{2}{ }^{\prime} k\right)}{k_{2}} \text { (Ref. 2). }
$$

If the assumption is made that $k>>k_{-2}$, the expression can be simplified to $\Phi_{2}=1 / k_{2}$, and $1 / \Phi_{2}$ can be equated with the rate constant for the formation of the intermediate ternary complex. However, as can be seen from the expression given above and which has been pointed out previously, ${ }^{2}$ this simplification requires the assumption $k_{2}{ }^{\prime}>>k^{\prime}$. Further evidence that such a simplification may be unrealistic is to be found in the results of Nygaard and Theorell ${ }^{27}$ and Mahler and Douglas ${ }^{6}$ for yeast alcohol dehydrogenase. Both suggested mechanisms in which the rate-determining step for the yeast enzyme reaction was the interconversion of the ternary complexes.

It can be seen from the data in Table 1 and in Fig. 6 that with an increase in the electron-withdrawing power of the para-substituent there is an increase in $1 / \Phi_{2}$. The value appears to decrease with electron-donating substituents, though the differences are small. Also, the range of negative $\sigma$ values is small. [Kinetic studies with $p$-dimethylaminobenzaldehyde $(\sigma=-0.83)$ were unsuccessful because of the almost complete quenching of NADH fluorescence by this substrate.] Such effects of substitution on the reactivity of the aldehyde substrate are consistent with a hydride transfer mechanism, as has been put forward for this enzyme..$^{6,8,9}$ Thus analogous effects of substitution have been observed in the Cannizzaro reaction ${ }^{12,13}$ and in model studies of the reduction of thiobenzophenone by $\mathrm{NADH} .^{7}$ Both reactions involve the direct transfer of hydrogen. In the model studies, $p$-methoxythiobenzophenone reacted more slowly than the unsubstituted thiobenzophenone. The introduction of electronwithdrawing substituents increased the reaction rate. It is apparent from the data in Fig. 6 that the Hammett plot is biphasic. Because of the relatively small number of points and the short range of negative $\sigma$ values considered, no attempt has been made to calculate values for $\varrho$ constants.

Studies similar the one reported here have been carried out with thiaminase, ${ }^{24}$ L-amino acid oxidase, ${ }^{23}$ and aldehyde dehydrogenase. ${ }^{19}$ The aldehyde dehydrogenase results are of particular interest in that the reactants are similar to those in the alcohol dehydrogenase reaction. In the one case aldehyde is converted to the corresponding acid and in the other to the alcohol. The Hammett plot of maximum velocity as a function of $\sigma$ for the aldehyde dehydrogenase reaction was clearly biphasic. ${ }^{19}$ This was observed also in the thiaminase ${ }^{24}$ and L-amino acid oxidase ${ }^{23}$ studies. Such a biphasic plot was taken as evidence for a change in mechanism or rater-determining step in the enzyme reaction as a function of reactant substitution. Biphasic Hammett plots can be diagnostic for such changes. ${ }^{25}$ Considering the relation between $\Phi_{2}$ and the rate constants for the formation and interconversion of the ternary complexes, one would expect a number of effects to be operative in determining the value of $\Phi_{2}$. Considering the known broad specificity of liver alcohol dehydrogenase, ${ }^{1}$ steric effects would be minimal for the substrates under consideration. However, the relative lipophilic nature of the substrate can

Acta Chem. Scand. 20 (1966) No. 7 
be highly significant. Thus $1 / \Phi_{2}$ is almost twenty times greater for butyraldehyde than acetaldehyde. ${ }^{22}$ In the present study the $1 / \Phi_{2}$ values observed are all greater than the value for acetaldehyde, ${ }^{22}$ and the substrates are more lipophilic. Such results are best explained on the basis of lipid solubility, as both butyraldehyde and benzaldehyde would be expected to be more stabilized relative to the excited polarized state from purely electronic considerations ${ }^{13}$ than acetaldehyde. Also, studies of the binding of amides which interact at the aldehyde binding site indicate that benzamide $\left(k_{\mathrm{ER}, \mathrm{I}}=0.61 \mathrm{mM}\right)$ is more tightly bound than acetamide $\left(k_{\mathrm{ER}, \mathrm{I}}=5.0 \mathrm{mM}\right)$ in the ternary complex ${ }^{30,31}$ These considerations are further strengthened by the recent report that better linear-free energy correlations can be made for enzyme reactions if terms for substrate lipophilicity and steric effects are included in the linearfree energy relationship. ${ }^{26}$

In correlating reactivity and lipid solubility, the free energy related substituent $\pi$ was defined as $\log \left(\mathrm{P}_{\mathrm{X}}-\mathrm{P}_{\mathrm{H}}\right)$, where $\mathrm{P}_{\mathrm{H}}$ is the partition coefficient of the parent molecule between 1-octanol and water and $P_{X}$ that of the derivative. ${ }^{25}$ From the data presented for various benzyl alcohols ${ }^{28}$ and assuming that the relative solubilities can be extrapolated to the aldehydes, some insight into the reasons for the deviations from linearity observed in Fig. 6 can be gained. In the case of the $p$-nitro- and $p$-chloro-derivatives, the relative $\pi$ values of 0.16 and 0.86 indicate that the relationship between lipid solubility is the reverse of that between the $\sigma$ values for these substrates. Similarly in the case of the $p$-methyl-derivative $(\pi=0.48)$, the lipid solubility is greater than for the unsubstituted compound, and as seen in Fig. 6 this may be a more dominant effect than the relative $\sigma$ values.

It can be concluded from the data presented here that $\Phi_{2}$ is most realistically considered as a complex function of rate constants for the formation and interconversion of ternary complexes. The dependence of $\Phi_{2}$ on the electronic structure of the aldehyde substrate is consistent with the postulate of a hydride transfer mechanism involving a metal atom-induced alcoholate ion intermediate. It is apparent also that $\Phi_{2}$ is dependent on substrate polarity.

Acknowledgement. The author is grateful to Professor Hugo Theorell for his advice and support throughout the course of this work. He is also grateful to the members of the staff of Biokemiska avdelningen, Medicinska Nobelinstitutet, for their gracious hospitality and to the Olsen Memorial Foundation, Utica, New York, for a personal fellowship. This work was supported by grants from the Swedish Medical Research Council and Institutet för Maltdrycksforskning.

\section{REFERENCES}

1. Sund, H. and Theorell, H. In Boyer, P. D., Lardy, H. and Myrbäck, K. The Enzymes, Academic, New York 1963, Vol. 7, p. 25.

2. Dalziel, K. J. Biol. Chem. 238 (1963) 2850.

3. Mahler, H. R., Baker, R. H., Jr. and Shiner, V. J., Jr. Biochemistry 1 (1962) 47.

4. Wratten, C. C. and Cleland, W. W. Biochemistry 2 (1963) 935.

5. Levy, H. R. and Vennesland, B. J. Biol. Chem. 228 (1957) 85.

6. Mahler, H. R. and Douglas, J. J. Am. Chem. Soc. 79 (1957) 1159.

7. Abeles, R. H., Hutton, R. F. and Westheimer, F. H. J. Am. Chem. Soc. 79 (1957) 712 . 
8. Wallenfels, K. and Sund, H. Angew. Chem. 67 (1955) 517, 787.

9. Wallenfels, K. and Sund, H. Biochem. Z. 329 (1957) 59.

10. Woodward, R. B., Wendler, N. L. and Brutschy, F. J. J. Am. Chem. Soc. 67 (1945) 1425.

11. Doering, W. von E. and Aschner, T. C. J. Am. Chem. Soc. 75 (1953) 393.

12. Molt, E. L. Rec. Trav. Chim. 56 (1937) 233.

13. Hine, J. Physical Organic Chemistry, McGraw, New York 1963.

14. Dalziel, K. Acta Chem. Scand. 11 (1957) 1706.

15. Theorell, H. and Yonetani, T. Arch. Biochem. Biophys., Suppl. 1 (1962) 209.

16. Dalziel, K. Acta Chem. Scand. 12 (1958) 459.

17. Dalziel, K. Acta Chem. Scand. 11 (1957) 397.

18. Theorell, H. Advan. Enzymol. 20 (1958) 31.

19. Dietrich, R. A., Hellerman, L. and Wein, J. J. Biol. Chem. 237 (1962) 560.

20. Barron, E. S. G. and Levine, S. Arch. Biochem. Biophys. 41 (1952) 175.

21. Treble, D. H. Biochem. J. 82 (1962) 129.

22. Dalziel, K. Biochem. J. 84 (1962) 244.

23. Radda, K. Nature 203 (1964) 936.

24. Mazrimas, J. A., Song, P., Ingraham, L. L. and Draper, R. D. Arch. Biochem. Biophys. 100 (1963) 409.

25. Wells, P. G. Chem. Rev. 63 (1963) 171.

26. Hansch, C., Deutsch, E. W. and Smith, R. W. J. Am. Chem. Soc. 87 (1965) 2738.

27. Nygaard, A. P. and Theorell, H. Acta Chem. Scand. 9 (1955) 1300.

28. Fujita, T., Iwasa, J. and Hansch, C. J. Am. Chem. Soc. 86 (1964) 5175.

29. Theorell, H. and McKinley-McKee, J. S. Acta Chem. Scand. 15 (1961) 1797.

30. Woronick, C. Acta Chem. Scand. 17 (1963) 1791.

31. Winer, A. D. and Theorell, H. Acta Chem. Scand. 14 (1960) 1729.

Received March 28, 1966. 